\title{
ANALISIS PEMETAAN DAERAH RAWAN BANJIR DI KOTA MEDAN TAHUN 2020
}

\author{
Nabila Anggraini ${ }^{1}$, Bobby Pangaribuan ${ }^{2}$, Asri Patria Siregar ${ }^{3}$, Ghannes Sintampalam ${ }^{4}$, Amri \\ Muhammad $^{5}$, M Ridha Syafii Damanik ${ }^{6}$, M Taufik Rahmadi ${ }^{7}$ \\ Jurusan Pendidikan Geografi, Fakultas Ilmu Sosial, Universitas Negeri Medan \\ Jl. Willem Iskandar Pasar V Medan Estate, Kota Medan, Sumatera Utara, 20221, Indonesia \\ *taufikrahmadi@unimed.com
}

\begin{tabular}{lrr}
\hline \multicolumn{2}{c}{ INFO ARTIKEL } \\
\hline \multicolumn{2}{l}{ Riwayat } & Artikel: \\
Dikirim & $:$ & $24-06-2021$ \\
Disetujui & $:$ & $12-08-2021$ \\
Diterbitkan & $:$ & $13-08-2021$
\end{tabular}

\section{Kata kunci:}

Pemetaan, Banjir, Kerawanan, Sistem Informasi Geografis

\begin{abstract}
ABSTRAK
Abstract: Medan City is one of the areas included in the flood-prone category in North Sumatra. This natural disaster always occurs every year when the rainy season enters. The purpose of this research is to map the level of flood hazard in Medan City. The type of method used in this study is a qualitative method by looking at the effect of each flood parameter to identify the level of flood vulnerability in Medan City. The parameters used are the slope of the slope, soil type, and rainfall which will then be processed using the overlay method to obtain the flood hazard class in Medan City. The results showed that the distribution of flood-prone areas in Medan City was in all parts of the area which were categorized into four levels of vulnerability, namely very low with an area of 248 hectares, low with an area of 1,817 hectares, medium with an area of 11,465 hectares, and high categories with an area of 14,037 hectares.
\end{abstract}

\begin{abstract}
Abstrak: Kota Medan adalah salah satu daerah yang termasuk dalam kategori rawan banjir di Sumatera Utara. Bencana alam ini selalu terjadi setiap tahun ketika memasuki musim penghujan. Tujuan penelitian ini adalah untuk melakukan pemetaan terhadap tingkat kerawanan banjir di Kota Medan. Jenis metode yang digunakan dalam penelitian ini adalah metode kualitatif dengan melihat pengaruh masing-masing parameter banjir untuk mengidentifikasi tingkat kerawanan banjir di Kota Medan. Parameter yang digunakan adalah kemiringan lereng, jenis tanah, dan curah hujan yang kemudian akan diolah dengan metode overlay untuk mendapatkan kelas kerawanan banjir di Kota Medan. Hasil penelitian menunjukkan bahwa persebaran daerah rawan banjir di Kota Medan terdapat diseluruh bagian wilayah yang dikategorikan menjadi empat tingkatan kerawanan yaitu sangat rendah dengan luas $248 \mathrm{Ha}$, rendah seluas $1.817 \mathrm{Ha}$, sedang dengan luas sebesar $11.465 \mathrm{Ha}$, dan kategori tinggi yang memiliki luas $14.037 \mathrm{Ha}$.
\end{abstract}




\section{PENDAHULUAN}

Banjir adalah sebuah peristiwa dimana daratan yang biasanya kering menjadi tergenang oleh air, yang disebabkan adanya curah hujan yang tinggi dan kondisi topografi wilayah yang rendah hingga cekungan, dan dapat juga disebabkan oleh rendahnya kemampuan infiltrasi oleh tanah, sehingga menyebabkan tanah tidak mampu lagi menampung dan menyerap air (Nuryanti et al, 2018). Menurut Darmawan et al, (2017) bencara banjir merupakan bencana alam yang paling sering terjadi, baik dilihat dari intensitasnya pada suatu tempat maupun jumlah lokasi kejadian dalam setahun yaitu sekitar $40 \%$ di antara bencana alam yang lainnya

Kota Medan merupakan ibu kota Provinsi Sumatera Utara yang berpenduduk 2.279.894 jiwa memiliki luas wilayah 26.510 ha $\left(265,10 \mathrm{~km}^{2}\right)$ atau $3,6 \%$ dari luas keseluruhan Provinsi Sumatera Utara (BPS Sumatera Utara, 2019). Kota Medan adalah salah satu daerah yang termasuk dalam kategori rawan banjir di Sumatera Utara. Bencana alam banjir selalu terjadi setiap tahun saat memasuki musim penghujan. Banjir di Kota Medan hampir rata-rata 10-12 kali/tahun yang sangat dipengaruhi oleh keadaan Sungai Deli dan Belawan di daerah hulu. Mencakup Kabupaten Karo, Kabupaten Deli Serdang dan Kota Medan, bencana banjir di Kota Medan diakibat oleh adanya kiriman dari sungai daerah hulu dan kondisi drainase kota yang sangat buruk (poor drainage) (Tampubolon, 2018).

Pemetaan daerah kerawanan banjir sangat perlu dilakukan sebagai masukan kepada pemerintah agar dapat mengambil kebijakan yang tepat sasaran dalam upaya untuk menanggulanginya. Penanggulangan banjir sudah dilakukan pada berbagai kota ya ada di dunia termasuk Indonesia seperti pembuatan drainase, sumur resapan dan berbagai metode lainnya tetapi tidak dapat berfungsi secara maksimal yang disebabkan oleh aktivitas manusia (Putra, 2015).

Salah satu metode yang dapat digunakan dalam pemetaan kerawanan banjir yaitu menggunakan Sistem Informasi Geografis (SIG). Sistem Informasi Geografis (SIG) merupakan salah satu cara dalam melakukan proses pemetaan, termasuk pembuatan peta daerah rawan banjir. Pemetaan daerah rawan banjir dapat dilakukan secara cepat dengan sistem informasi geografi dengan menggunakan metode tumpang susun atau overlay terhadap parameter-parameter banjir, seperti jenis tanah, curah hujan, dan kemiringan lereng (Nuryanti et al, 2018). Dengan sistem informasi geografi diharapkan akan mempermudah penyajian informasi spasial khususnya yang terkait dengan penentuan tingkat kerawanan banjir sehingga lebih mudah dalam mengidentifikasi daerahdaerah mana saja yang sering menjadi sasaran banjir.

\section{METODE PENELITIAN}

Penelitian ini merupakan penelitian studi literatur dengan batas daerah kajian adalah administrasi Kota Medan yang secara geogarfis terletak pada koordinat $330^{\prime}-3^{\circ} 43^{\prime} \mathrm{LU}$ dan 9835'-9844' BT yang berada di Provinsi Sumatera Utara. Waktu pelaksanaan penelitian ini adalah pada bulan Desember tahun 2020 di Kota Medan.

Jenis metode yang digunakan dalam penelitian ini adalah metode kualitatif dengan melihat pengaruh dari parameter banjir yang digunakan untuk mengidentifikasi tingkat kerawanan banjir di Kota Medan. Tahap-tahap penelitian ini adalah:

1. Penentuan parameter kerawanan banjir.

Parameter kerawanan banjir yang digunakan dalam penelitian ini terdiri atas kemiringan lereng, jenis tanah, dan curah hujan.

\section{Pengumpulan Data}

Data yang dikumpulkan yaitu data citra DEM SRTM 30 M Sumatera Utara, data jenis tanah Sumatera Utara tahun 2019, dan data curah hujan Kota Medan tahun 2019 (Badan Pusat Statistik Sumatera Utara, 2019). Ketiga data tersebut kemudian diolah menjadi peta yang akan menjadi data input dalam proses selanjutnya.

\section{Overlay Data}

Beberapa data yang telah dikumpulkan kemudian di overlay. Adapun peta yang dioverlay yaitu peta kelerengan, peta jenis tanah, dan peta curah hujan Kota Medan. Proses overlay ini, menggunakan bantuan aplikasi pemetaan yaitu Arcgis 10.8. 
4. Skoring Parameter Kerawanan Banjir.

Skoring yang dilakukan bertujuan untuk memberikan nilai dari poligon-poligon wilayah yang memiliki kesamaan karakteritik pada setiap parameter. Selain itu, skoring juga dilakukan untuk memberikan nilai pada wilayah-wilayah yang didapatkan dari hasil overlay. Nilai skoring yang digunakna berdasarkan dengan Peraturan Menteri Kehutanan Republik Indonesia Nomor P.32/MENHUTII/2009.

5. Klasifikasi Daerah Rawan Banjir Dalam menentukan klasifikasi tingkatan kerawanan banjir menggunakan rumus:

$$
K=\frac{J T-J R}{J K}
$$

Keterangan:

- $\mathrm{K}=$ Interval Kelas

- $\mathrm{JT}=$ Jumlah Tertinggi (Bobot $\mathrm{x}$ Skor Tertinggi Setiap Parameter)

- $\mathrm{JR}=$ Jumlah Terendah (Bobot $\mathrm{x}$ Skor Terendah Setiap Parameter)

- $\mathrm{JK}=$ Jumlah Kelas

\section{HASIL DAN PEMBAHASAN \\ Peta Kemiringan Lereng}

Kemiringan lereng mempengaruhi jumlah dan kecepatan limpasan permukaan, drainase permukaan, penggunaan lahan dan erosi. Jika lahan tergolong landai kemiringan lerengnya, maka aliran limpasan permukaan akan menjadi lambat sehingga besar kemungkinan terjadinya genangan atau banjir, sebaliknya semakin curam kemiringan lereng dapat menyebabkan aliran limpasan permukaan menjadi cepat sehingga air hujan yang jatuh akan langsung dialirkan dan tidak menggenangi daerah tersebut, sehingga resiko banjir menjadi lebih kecil (Nuryanti et al, 2018).

Pengelolahan peta kemiringan lereng didapatkan dari pengolahan data Citra DEM SRTM 30 M Kota Medan. Parameter kemiringan lereng di Kota Medan dibagi menjadi tiga kelas yaitu sangat curam (>40\%), curam (25-40\%), agak curam (15-25\%), landai (8-15\%), dan datar (0-8\%). Kemiringan lereng di Kota Medan hampir secara keseluruhan tergolong datar $(0-8 \%)$ dan landai $(8-15 \%)$.

\section{Peta Jenis Tanah}

Jenis tanah adalah salah satu faktor yang penting untuk menentukan daerah rawan banjir, dikarenakan sangat berpengaruh terhadap proses infiltrasi. Jenis tanah yang memiliki tekstur halus menunjukkan tingkat infiltrasi yang rendah karena dapat menimbulkan aliran permukaan (run off) tinggi. Sebaliknya, jika jenis tanah yang bertekstur kasar maka memiliki daya infiltrasi yang tinggi. Sehingga aliran permukaan (run off) yang terbentuk semakin rendah (Matondang et al, 2013). Parameter jenis tanah di Kota Medan dibagi menjadi lima kelas daya infiltrasi yaitu besar (latosol, organosol, dan renzina), agak besar (andosol, inceptisol, dan entisol), sedang (regosol fan alfisol), agak kecil (latosol), dan kecil (aluvial, planosol, dan hidromof kelabu). Jenis tanah yang terdapat di Kota Medan adalah inceptisol, oxisols, ultisols, dan entisol. Namun, jenis tanah yang mendominasi di Kota Medan adalah inceptisol dan entisol yang termasuk dalam kelas dengan daya infiltrasi agak besar.

\section{Peta Curah Hujan}

Curah hujan adalah besarnya volume air yang jatuh pada suatu areal tertentu, beesarnya curah hujan dapat dinyatakan dalam $\mathrm{m}^{3}$ per satuan luas atau secara umum dinyatakan dalam tinggi kolam air (Asdak, 2010). Curah hujan berpengaruh terhadap potensi terjadinya banjir, jika suatu daerah memiliki curah hujan tinggi maka semakin tinggi potensi terjadinya banjir. Dan begitu sebaliknya, semakin rendah curah hujannya maka potensi terjadinya banjir juga rendah (Darmawan, 2017). Berdasarkan data Badan Pusat Statistik Sumatera Utara tahun 2019, terdapat tiga stasiun atau titik perhitungan curah hujan yang terdapat di Kota Medan. Yaitu Stasiun BMKG Belawan, Stasiun BMKG Deli Serdang, dan Statsiun BMKG Wilayah I Kota Medan. Parameter curah hujan di Kota Medan dibagi menjadi lima kelas yaitu sangat rendah $(<2500 \mathrm{~mm} /$ tahun $)$, rendah (2500 - $3500 \mathrm{~mm} /$ tahun), sedang (3500 - 4500 $\mathrm{mm} /$ tahun), tinggi (4500 - $5500 \mathrm{~mm} /$ tahun), dan sangat tinggi (> $5500 \mathrm{~mm} /$ tahun). Curah hujan di Kota Medan secara keseluruhan berada pada kelas rendah $(2500-3500$ $\mathrm{mm} / \mathrm{tahun})$ dan sangat rendah $(<2500$ $\mathrm{mm} /$ tahun). 


\section{Pemetaan Kerawanaan Banjir}

Pemetaan kerawanan banjir

didapatkan dengan menggabungkan tiga parameter penyebab banjir yaitu peta kemiringan lereng, peta jenis tanah, dan peta curah hujan. Ketiga peta tersebut dioverlay. Untuk lebih jelasnya dapat dilihat pada Tabel 1 berikut ini.

Tabel 1. Nilai Pembobotan Setiap Parameter

\begin{tabular}{c|l|c}
\hline No & \multicolumn{1}{|c|}{ Parameter } & Bobot \\
\hline 1 & Kemiringan Lereng & 50 \\
2 & Jenis Tanah & 30 \\
3 & Curah Hujan & 20 \\
\hline
\end{tabular}

Sumber: RTKRLH-DAS, 2009.

Peta hasil proses overlay dari ketiga parameter tersebut kemudian diklasifikasikan menjadi lima kelas tingkat kerawanan banjir yaitu sangat rendah, rendah, sedang, tinggi, dan sangat tinggi. Untuk lebih jelasnya klasifikasi tingkat kerawanan banjir dapat dilihat pada Tabel 2 berikut.

Tabel 2. Klasifikasi Tingkat Kerawanan Banjir

\begin{tabular}{c|l|c}
\hline No & $\begin{array}{c}\text { Klasifikasi Kelas } \\
\text { Kerawanan }\end{array}$ & $\begin{array}{c}\text { Interval } \\
\text { Total } \\
\text { Skoring }\end{array}$ \\
\hline 1 & Sangat Rendah & $\leq 160$ \\
2 & Rendah & $161-220$ \\
3 & Sedang & $221-280$ \\
4 & Tinggi & $281-340$ \\
5 & Sangat Tinggi & $\geq 341$ \\
\hline
\end{tabular}

Sumber: Hasil Analisis Data, 2020.

Berdasarkan Peta tingkat kerawanan banjir di Kota Medan dibagi dalam empat kelas yaitu kelas dengan tingkat kerawanan sangat rendah, rendah, sedang, dan tinggi. Luas wilayah pada kelas dengan tingkat kerawanan banjir yang sangat rendah yaitu $248 \mathrm{Ha}$. Untuk kelas rendah seluas $1817 \mathrm{Ha}$, pada kelas kerawanan banjir sedang mencapa $11.465 \mathrm{Ha}$, dan untuk kelas tinggi seluas $14.307 \mathrm{Ha}$.

Tabel 3. Klasifikasi Tingkat Kerawanan Banjir Kota Medan

\begin{tabular}{c|l|c}
\hline No & Kelas Kerawanan & Luas (Ha) \\
\hline 1 & Sangat Rendah & 248 \\
2 & Rendah & 1.817 \\
3 & Sedang & 11.465 \\
4 & Tinggi & 14.037 \\
\hline \multicolumn{2}{|c}{ Total } & 27.567 \\
\hline
\end{tabular}

Sumber: Hasil Analisis Data, 2020

Berdasarkan hasil pemetaan daerah rawan banjir yang dilakukan, secara keseluruhan Kota Medan merupakan daerah yang mempunyai potensi banjir yang besar. Dimana tingkat kerawanan banjir di Kota Medan yang secara keseluruhan terletak pada kelas sedang dan tinggi, yang dapat dilihat dari warna merah dan kuning yang mendominasi di seluruh wilayah Kota Medan. Hal ini disebabkan oleh kelas kemiringan lereng yang mendapatkan nilai pembobotan paling tinggi secara keseluruhan berada di kelas datar (0$8 \%$ ). Daerah yang memiliki kelerengan dengan $0-8 \%$ pada umumnya menjadi tempat tergenangnya air yang jika dalam volume besar, sehingga dapat menimbulkan kerugian karena tergolong sebagai bencana banjir (Asdak, 2010). Kelerengan 0-8 \% merupakan suatu bentuk permukaan yang datar dan berpengaruh pada melambatnya kecepatan aliran air yang mengalir disuatu lahan. Kecamatan Medan Belawan dan Medan Labuhan merupakan daerah dengan tingkat kerawanan banjir yang tinggi. Sedangkan Medan Johor dan Medan Tuntungan merupakan daerah dengan kelas kerawanan banjir sedang. Untuk lebih jelasnya tingkat kerawanan banjir berdasarkan parameterparameter tersebut dapat dilihat pada Gambar $1-4$ Berikut. 


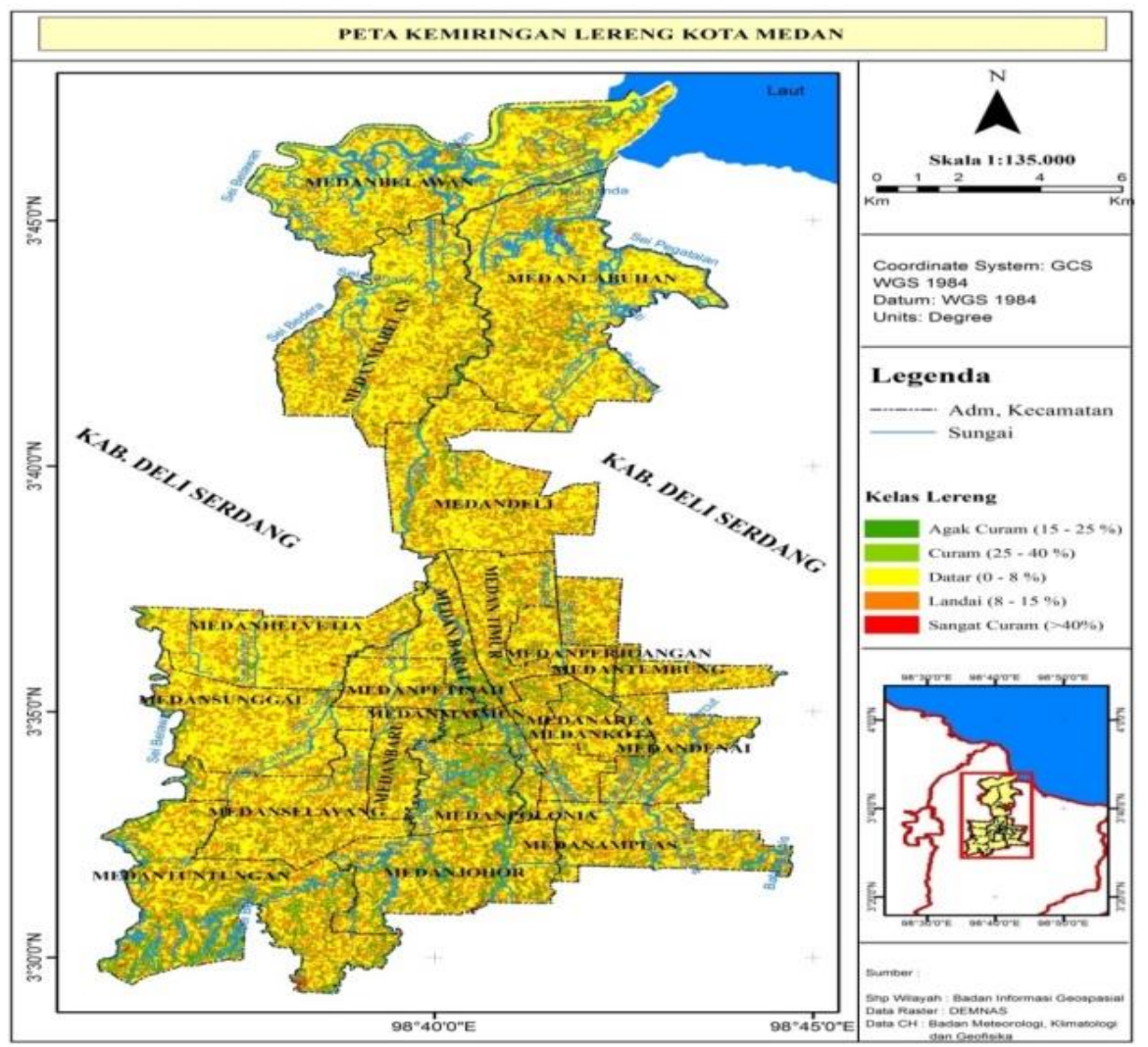

Gambar 1. Peta Kemiringan Lereng Kota Medan

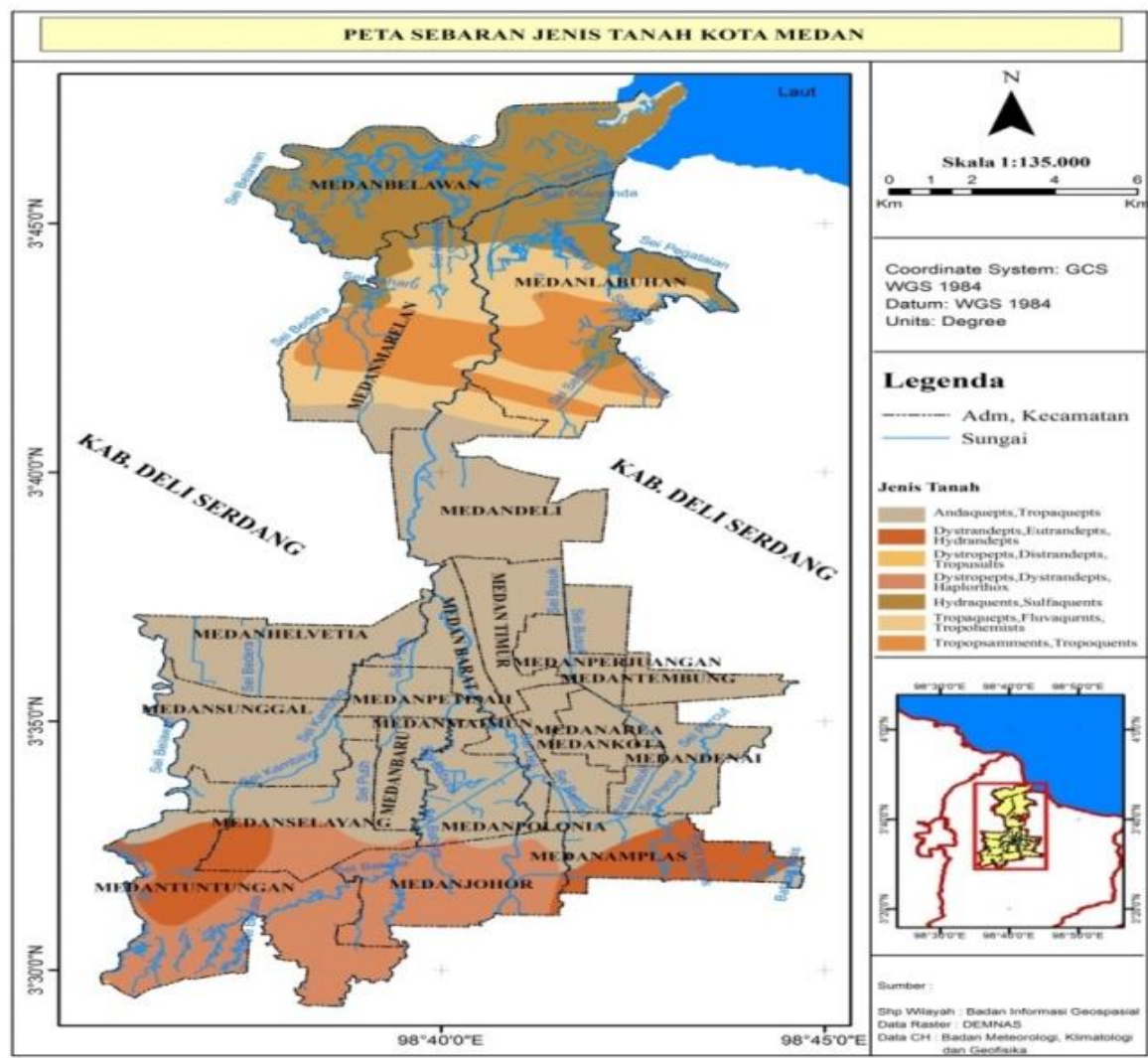

Gambar 2. Peta Jenis Tanah Kota Medan 


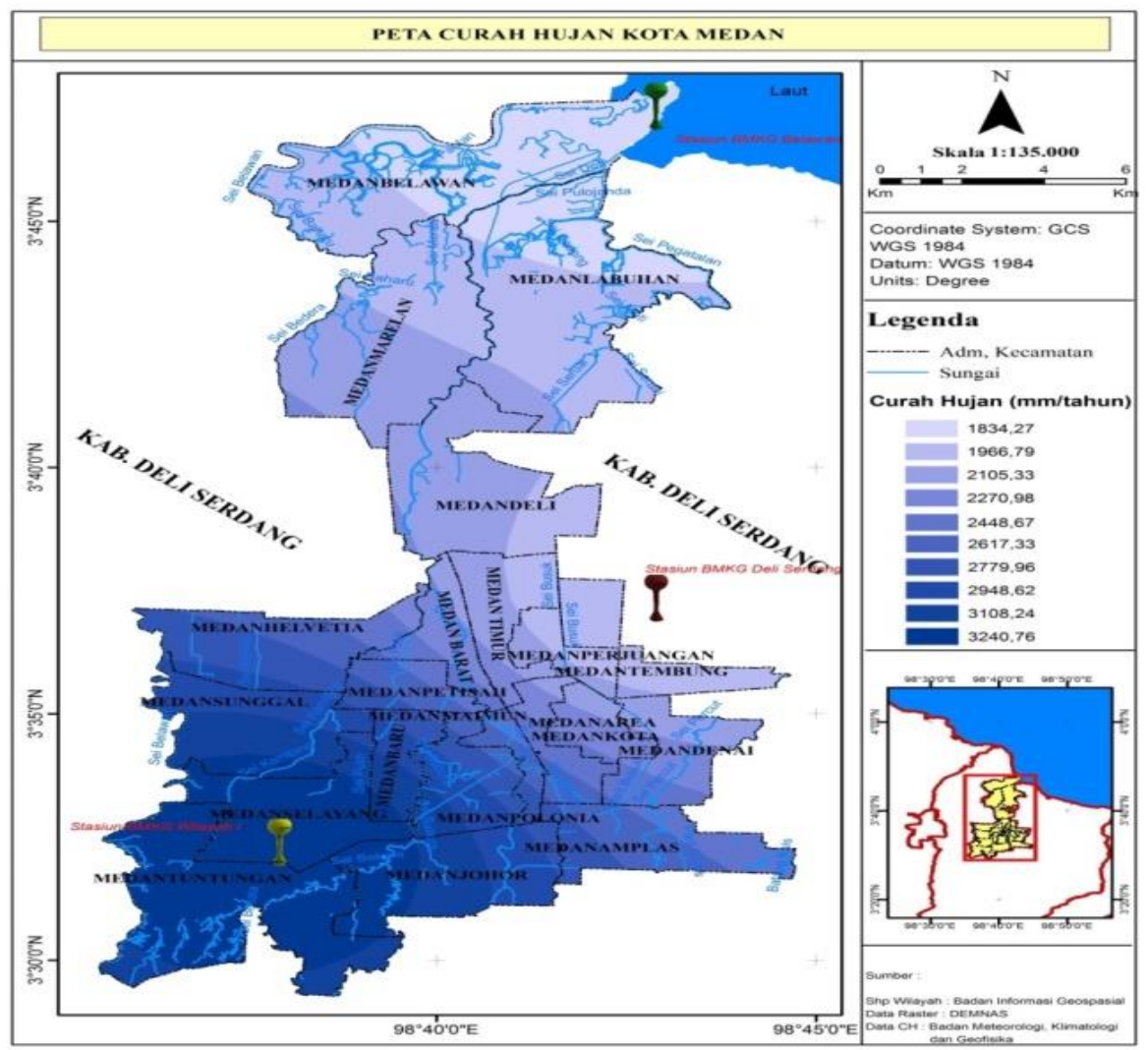

Gambar 3. Peta Curah Hujan Kota Medan

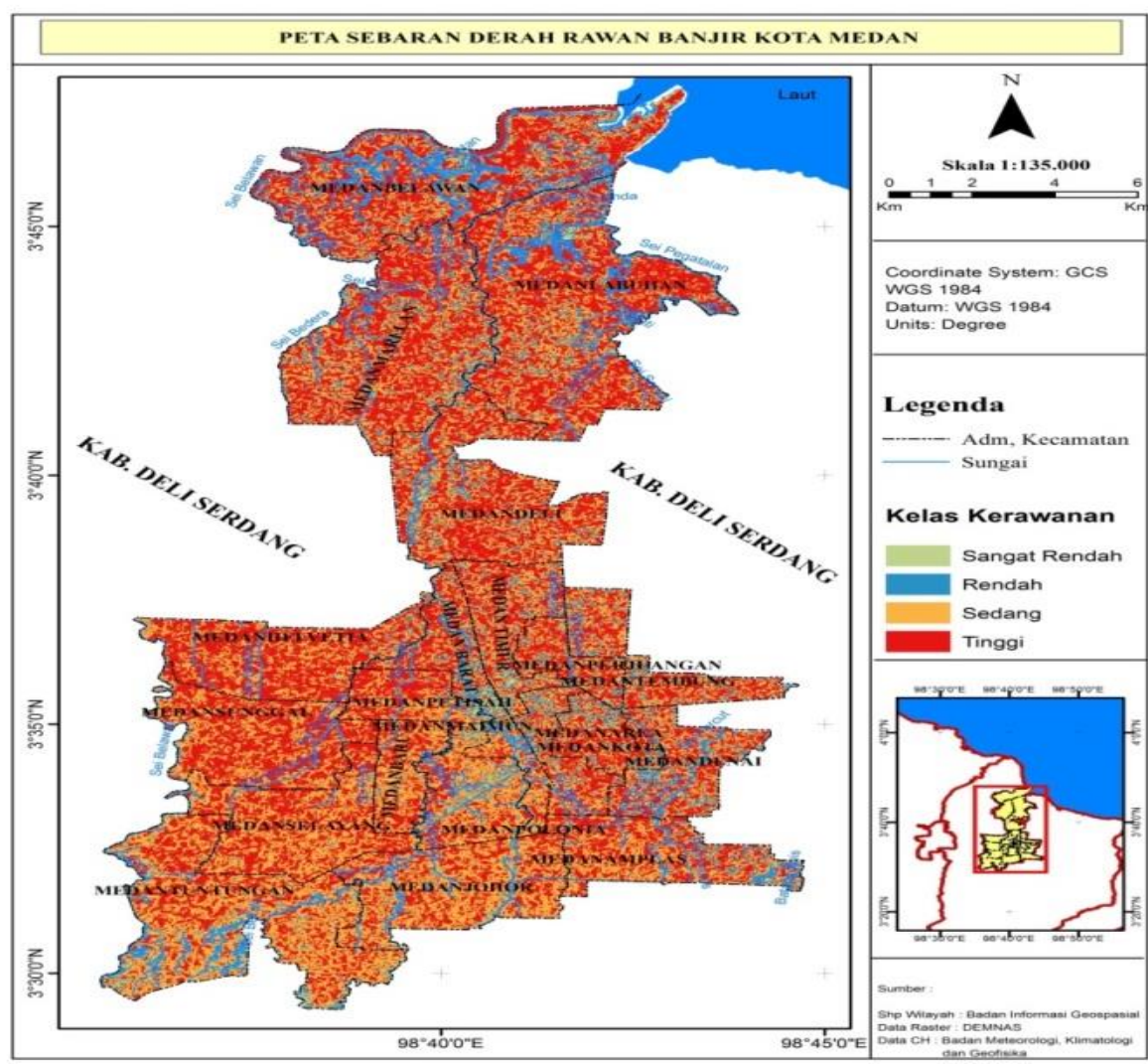

Gambar 4. Peta Daerah Rawan Banjir Kota Medan 


\section{SIMPULAN}

1. Persebaran daerah rawan banjir di Kota Medan terdapat diseluruh bagian wilayah yang dikategorikan menjadi empat tingkatan kerawanan yaitu sangat rendah dengan luas $248 \mathrm{Ha}$, rendah seluas 1.817 $\mathrm{Ha}$, sedang dengan luas sebesar $11.465 \mathrm{Ha}$, dan kategori tinggi yang memiliki luas $14.037 \mathrm{Ha}$.

2. Kecamatan Medan Belawan dan Medan Labuhan merupakan daerah dengan tingkat kerawanan banjir yang tinggi. Sedangkan Medan Johor dan Medan Tuntungan merupakan daerah dengan kelas kerawanan banjir sedang.

3. Faktor dominan yang menjadi penyebab kerawanan banjir di Kota Medan adalah kemiringan lereng. Selain memiliki bobot yang besar yaitu dengan nilai 50, sebaran kemiringan $0-8 \%$ (datar) hampir terdapat diseluruh wilayah Kota Medan yang mempunyai kategori sedang dan tinggi terjadinya banjir.

\section{DAFTAR PUSTAKA}

Arsyad, S. (2010). Konservasi Tanah Dan Air (2nd Ed.). Bogor: IPB Press.

Asdak, C. (2010). Hidrologi Dan Pengelolaan Daerah Aliran Air Sungai: Edisi Revisi Kelima. Yogyakarta: Gadjah Mada University Press Yogyakarta.

Binawan, B. P., \& Junaedi, D. (2017). Aplikasi GIS Klasifikasi Tingkat Kerawanan Banjir Wilayah Kabupaten Bandung Menggunakan Metode Weighted Product. Indonesia Journal on Computing (Indo-JC), 2(1), 59-70.

Darmawan, K., \& Suprayogi, A. (2017). Analisis Tingkat Kerawanan Banjir Di Kabupaten Sampang Menggunakan Metode Overlay Dengan Scoring Berbasis Sistem Informasi Geografis. Jurnal Geodesi Undip, 6(1), 31-40.

Hamdani, H., Permana, S., \& Susetyaningsih, A. (2014). Analisa Daerah Rawan Banjir
Menggunakan Aplikasi Sistem Informasi Geografis (Studi Kasus Pulau Bangka). Jurnal Konstruksi, 12(1).

Hamdikatama, B. (2020). Pemetaan Daerah Rawan Banjir di Kota Surakarta Menggunakan Sistem Informasi Geografis. IJNS-Indonesian Journal on Networking and Security, 9(1).

Hernoza, F., Susilo, B., \& Erlansari, A. (2020). Pemetaan Daerah Rawan Banjir Menggunakan Penginderaan Jauh Dengan Metode Normalized Difference Vegetation Index, Normalized Difference Water Index Dan Simple Additive Weighting (Studi Kasus: Kota Bengkulu), Rekursif: Jurnal Informatika, 8(2).

Matondang, J. P., Kahar, S., \& Sasmito, B. (2013). Analisis Zonasi Daerah Rentan Banjir Dengan Pemanfaatan Sistem Informasi Geografis (Studi Kasus: Kota Kendal Dan Sekitarnya). Jurnal Geodesi Undip, 2(2).

Nuryanti, N., Tanesib, J. L., \& Warsito, A. (2018). Pemetaan Daerah Rawan Banjir Dengan Penginderaan Jauh Dan Sistem Informasi Geografis Di Kecamatan Kupang Timur Kabupaten Kupang Provinsi Nusa Tenggara Timur. Jurnal Fisika: Fisika Sains Dan Aplikasinya, 3(1), 73-79.

Putra, S. B. S., \& Murti, S. H. (2015). Aplikasi Penginderaan Jauh Dan Sistem Informasi Geografis Untuk Pemetaan Daerah Rawan Banjir Di Kota Malang. Jurnal Bumi Indonesia, 4(1), 222869.

Saputro, A. F. (2019). Studi Pemetaan Daerah Rawan Banjir Dengan Metode Skoring Dan Pembobotan Pada Daerah Kota Tarakan (Studi Kasus: Kelurahan Selumit Dan Kelurahan Karang Balik).

Tampubolon, K. (2018). Aplikasi Sistem Informasi Geografis (SIG) Sebagai Penentuan Kawasan Rawan Banjir Di Kota Medan. Jurnal Pembangunan Perkotaan, 6(2), 63-68. 